\title{
Physical activity during pregnancy and its influence on delivery time: a randomized clinical trial
}

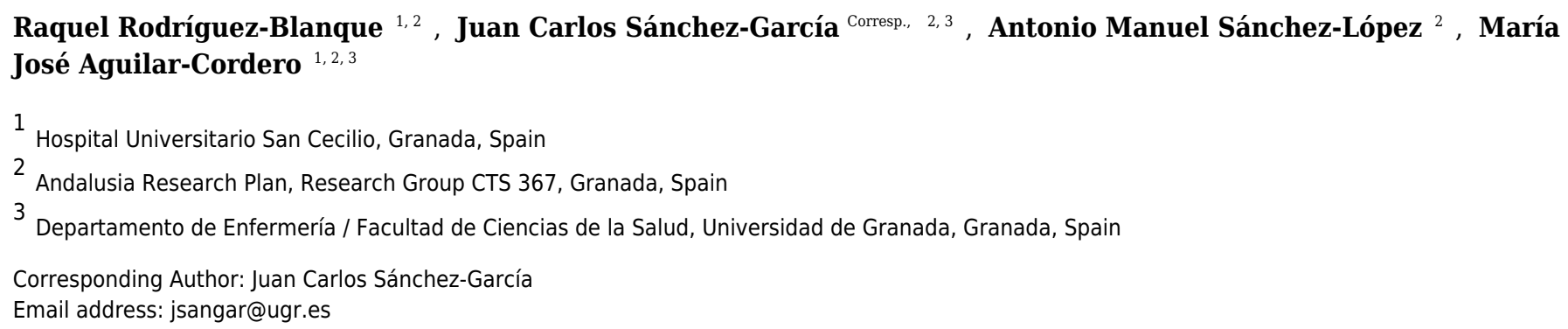

Introduction During pregnancy, women often change their lifestyle for fear of harmful effects on the child or themselves. In this respect, many women reduce the amount of physical exercise they take, despite its beneficial effects. Objective To determine the duration of labor in pregnant women who completed a program of moderate physical exercise in water and subsequently presented eutocic birth. Methods A randomized trialwas performed with 140 healthy pregnant women, divided into an exercise group (EG) $(n=70)$ and a control group (CG) $(n=70)$. The women who composed the study population were recruited at 12 weeks of gestation. The intervention program, termed SWEP (Study of Water Exercise during Pregnancy) began in week 20 of gestation and ended in week 37. Perinatal outcomes were determined by examining the corresponding partographs, recorded by the Maternity Service at the Granada University Hospital Complex. Results The intervention phase of the study took place from June through October 2016, with the 120 women finally included in EG and CG (60 in each group). At term, 63\% of the women in EG and $56 \%$ of those in CG had a eutocic birth. The average total duration of labor was $389.33 \pm 216.18 \mathrm{~min}$ for the women in EG and $561.30 \pm 199.94 \mathrm{~min}$ for those in CG, a difference of approximately three hours $(p<0.001)$. Conclusions The women who exercised in water during their pregnancy presented a shorter duration of labor than those who did not. The difference was especially marked with respect to the duration of the first and second stages of labor. 
1

2

Physical activity during pregnancy and its influence on delivery time: a randomized clinical

trial.

\section{Authors:}

Rodriguez-Blanque, Rª; Sánchez-García, JC b; MJ; Sánchez-López, AMº; Aguilar-Cordero, MJc. (1)

a. PhD. Hospital Universitario San Cecilio. Research Group CTS 367. Andalusia Research Plan. Junta de Andalucía. Granada, Spain.

b. PhD. Research Group CTS 367. Andalusia Research Plan. Junta de Andalucía. Granada, Spain.

c. Ph.D. School of Nursing. School of Health Sciences. University of Granada. Hospital

3

4
Universitario San Cecilio. Research Group CTS 367. Andalusia Research Plan. Junta de Andalucía. Facultad de Ciencias de la Salud, Universidad de Granada. Granada, Spain.

Correspondence to: PhD. Juan Carlos Sánchez-García. PhD. Research Group CTS 367.

Andalusia Research Plan. Junta de Andalucía. Granada, Spain. Tel: +34-629-542-224. E-mail:

jcsg750@gmail.com

\section{Introduction}

During pregnancy, women often change their lifestyle for fear of harmful effects on the child or themselves. In this respect, many women reduce the amount of physical exercise they take, despite its beneficial effects.

\section{Objective}

To determine the duration of labor in pregnant women who completed a program of moderate physical exercise in water and subsequently presented eutocic birth. 


\section{Methods}

28 A randomized trial was performed with 140 healthy pregnant women, divided into an 29 exercise group (EG) $(n=70)$ and a control group $(C G)(n=70)$. The women who composed the study 30 population were recruited at 12 weeks of gestation. The intervention program, termed SWEP

31 (Study of Water Exercise during Pregnancy) began in week 20 of gestation and ended in week 37.

32 Perinatal outcomes were determined by examining the corresponding partographs, recorded by the 33 Maternity Service at the Granada University Hospital Complex.

\section{Results}

The intervention phase of the study took place from June through October 2016, with the 120 women finally included in EG and CG (60 in each group). At term, 63\% of the women in EG and $56 \%$ of those in CG had a eutocic birth. The average total duration of labor was $389.33 \pm 216.18$ min for the women in EG and 561.30 \pm 199.94 min for those in $C G$, a difference of approximately three hours $(\mathrm{p}<0.001)$.

\section{Conclusions}

The women who exercised in water during their pregnancy presented a shorter duration of labor than those who did not. The difference was especially marked with respect to the duration of the first and second stages of labor.

\section{Introduction}

Although regular physical exercise is known to produce many health benefits, at all stages

of life, doubts have been expressed regarding its appropriateness during pregnancy, and about the type, frequency, intensity and duration of such exercise ${ }^{1}$.

During pregnancy, the body undergoes many changes, primarily affecting the locomotor 
50 system, and exercise routines must be modified. However, lack of knowledge in this respect often

51 makes health care personnel extremely cautious in their recommendations ${ }^{2}$.

52 Sedentarism and obesity are aspects of a major public health problem, one that also affects

53 women of childbearing age. During pregnancy, many women are strongly motivated to make

54 changes in their lifestyle. This intention, together with the provision of appropriate information

55 and advice from health care professionals, will help them acquire habits beneficial to their own 56 health and that of their babies.

Recent studies have shown that exercise during pregnancy prevents excessive weight gain ${ }^{3}$, gestational diabetes ${ }^{4}$, and high blood pressure ${ }^{5}$. It benefits not only the mother but also the fetus, since it reduces the risk of macrosomia ${ }^{4}$ and lowers the risk of premature birth ${ }^{6}$. All of these factors promote physiological delivery?

Exercising in water during pregnancy offers many advantages. For example, submergence in water decreases body weight and facilitates movement, thus preventing overload on the joints and back. Furthermore, exercising in water enables the woman to focus on breathing - rhythm, phases, volume, and type of respiration. These benefits are relevant to the subsequent stages of labor and delivery ${ }^{8}$.

We hypothesize that the practice of moderate physical exercise in water, following the guidelines of the SWEP (Study of Water Exercise during Pregnancy) method, will both improve aerobic capacity and also strengthen the muscles involved in childbirth (those of the abdomen and lower back), thus enhancing their performance during the second stage of labor.

\section{Study aim}

To determine the duration of labor in pregnant women who completed a program of moderate physical exercise in water and subsequently presented eutocic birth. 


\section{Material and method}

An open-label randomized controlled trial was conducted, in which both the subjects and the investigators were aware of the intervention. This trial complied with the CONSORT standards published in 2010 (“CONSORT Checklist”, 2017). It was approved by the Research Ethics Committee for the province of Granada, and assigned File No. SWEP-13-06. At all times, the study was conducted in accordance with the provisions of the Declaration of Helsinki, as amended at the 64th WMA General Assembly, Fortaleza, Brazil, October 2013. Written informed consent was obtained from all participants.

The trial is registered at the US National Institutes of Health (ClinicalTrials.gov), under the title "Physical Activity in Pregnancy and Postpartum Period, Effects on Women", Number NCT02761967.

\section{Participants}

The women who took part in this study were recruited at the Clinical Management Unit in La Zubia, which belongs to the Metropolitan Health Care District of Granada, Spain. This Unit has five health centers and an outpatients' clinic. In Spain, woman of childbearing age with amenorrhea normally attend their local health center to diagnose pregnancy. At the centers in question, potential recruits were informed about the study and those who expressed interest were asked to provide contact details. Subsequently, the midwife responsible for the recruitment of study participants telephoned to arrange an appointment at the patient's ultrasound clinic, during week 12 of gestation (these appointments took place in March and April 2016).

Contact was made with 364 potential participants. Of these women, 224 were excluded from consideration for inclusion in the study: 122 did not meet the inclusion criteria, 82 refused to 
95 participate (no reasons stated) and 20 cited personal reasons, such as fear of physical exercise

96 during pregnancy, family responsibilities or lack of time due to their employment.

97 The final sample, thus, consisted of 140 pregnant women, aged between 21 and 43 years,

98 who were divided into two subgroups: Exercise Group (EG) and Control Group (CG), with 70

99 women in each.

100 The following inclusion conditions were applied for participation in the study: good health,

101 with an uncomplicated singleton gestation; presenting none of the absolute contraindications

102 described in Box 1 of ACOG document number $650^{1}$, including heart disease, restrictive lung

103 disease, cervical incompetence, risk of preterm birth, second or third-trimester persistent bleeding,

104 preterm labor during current pregnancy, rupture of membranes, preeclampsia or pregnancy-

105 induced hypertension or severe anemia. In the case of a relative contraindication, a favorable report

106 from the patient's obstetrician was required for participation in the study. If warning signs were

107 observed, suggesting that physical exercise should be suspended during pregnancy, the patient's

108 gynecologist was consulted about the advisability of continuing with the program.

As the study data were obtained from the University Hospital Complex of Granada, Spain,

110 giving birth in a different hospital was a further criterion for exclusion.

111 The data for the participants were obtained at the Health Centers of the Metropolitan Health

112 District of Granada, Spain. The clinical data on the birth process - labor and birth - were obtained

113 from the partograph, a graphic record of the evolution of labor obtained from the mother's clinical

114 history, held at the hospital. The province of Granada has two public hospitals for maternal and

115 child health care. Both apply the same health care policies for childbirth, in accordance with

116 published guidelines for normal delivery9. The protocols for health care during childbirth can be

117 consulted via the following links: 
118 San Cecilio University Hospital:

119 https://www.husc.es/especialidades/ginecologia_y_obstetricia/guias_y_protocolos_asistenciales 120

121 Virgen de las Nieves University Hospital:

122 https://www.huvn.es/asistencia_sanitaria/ginecologia_y_obstetricia

\section{Intervention}

The women in EG performed moderate physical exercise in water, following the SWEP

125 guidelines. This exercise provides two main benefits; it improves aerobic capacity and it

126 strengthens the muscles especially involved in childbirth, as well as those in the abdomen and

127 lower back. This results in better muscle tone in the areas of the body most subject to tension

128 during pregnancy, and is excellent preparation for labor, generating increased lung capacity and

129 greater strength and resilience of the muscles involved in each stage of childbirth ${ }^{10}$. The SWEP

130 method is applied from weeks 20 to 37 of pregnancy and consists of three 60-minute sessions per

131 week, each with 45 minutes' activity followed by 15 minutes' relaxation. The sessions are based

132 on three phases: first, the warm-up, followed by the main phase, with aerobic movements and

133 strength-endurance exercises, designed specifically for pregnant women, and a final phase of

134 stretching and relaxation. The sessions take place in the mornings, after adequate caloric intake

135 and hydration.

136 The warm-up phase is firstly general, performed out of the water, and then specific, in the

137 water and with exercises appropriate to those which will follow. The aerobic element of the

138 exercise is designed to be performed in a 25 -meter pool where the women can perform swimming

139 exercises adapted to the corresponding phase of their pregnancy. The strength and resistance

140 exercises are then carried out in a pool 10 meters long and 1.50 meters deep, and are also adapted

141 to the women's stage of pregnancy. ${ }^{10}$. 
143 general guidance from the midwife about the positive effects of physical exercise. The participants

144 in CG had regular meetings with health providers (midwives, obstetricians, and family physicians)

145 during their pregnancy, as did those in EG.

146 Expected results and study instruments

147 Sociodemographic and anthropometric variables

148 Age, height, weight during first and third trimesters, weight gain and parity.

$149 \quad$ Physical effort exerted and level of intensity

150 The perceived effort and intensity of exercise were measured using the Borg Rating of

151 Perceived Exertion" (according to which a score of 12-14 is classed as "somewhat hard") in order

152 to ensure the moderate nature of the exercise performed, which at all times was in accordance with

153 ACOG recommendations ${ }^{1}$.

154 The participants' heart rate during the training sessions was monitored using a Quirumed 155 OXYM2000 portable pulse oximeter, to measure pulse and oxygen saturation. Heart rate was 156 determined at the end of each exercise session for the women who produced a value $>14$ on the 157 Borg Scale.

\section{$158 \quad$ Perinatal results}

A graphic record of the evolution of labor in each case was obtained by means of a

160 partograph ${ }^{12-17}$. The partograph was used to determine the following variables: administration of

161 oxytocin, anesthesia during labor (epidural or subdural), duration of gestation (days), neonatal

162 birthweight, skin-skin contact and duration of the first, second, and third stages of labor. The first

163 stage of labor is the time elapsed from 4 to $10 \mathrm{~cm}$. of dilation; the second stage is the time elapsed

164 from then until full dilation is reached and fetal expulsion occurs; and the third stage is the time 
165 elapsed from then until expulsion of the placenta and the membranes. In our analysis, the weeks

166 of gestation were transformed into days of gestation until the delivery took place.

167 The type of birth was also noted, but only in order to determine the percentages of eutocic,

168 instrumental or cesarean birth. In our calculation of the duration of labor, only births that ended

169 spontaneously (i.e. excluding instrumental births and cesarean sections) were taken into account.

170 The duration of labor was defined as the sum of the durations of the first, second, and third stages

171 defined above.

\section{Sample size}

173 The necessary sample size was calculated taking into account the previous findings of

174 Barakat, Lucía \& Ruiz (2009) ${ }^{18}$, who also studied the impact of a program of physical exercise for

175 women during the second and third trimesters of pregnancy and who highlighted the benefits of 176 participation in such a program, for the mother and for the child. In order to obtain a statistical

177 power of $80 \%$ to detect differences in the test of the null hypothesis $H_{0}: \mu_{1}=\mu_{2}$, using Student's

178 t-test for two independent samples, with a 5\% level of significance and a joint standard deviation

179 of 2.67, we calculated that a sample of at least 136 women would be needed, with 68 in each study 180 group.

\section{Randomization}

182 The sample allocation procedure was randomized as follows: each woman who arrived at 183 the health center and met the inclusion criteria was assigned a ticket bearing a serial number, by

184 the researcher responsible for recruitment. The ticket was then placed in an opaque envelope, and 185 the envelope in a container. When all the envelopes were in the container, the Principal Investigator 186 removed 70 envelopes, which were assigned to EG, and the remaining 70 were assigned to CG. 


\section{Statistical analysis}

188 The normality of the distribution of the numerical variables was tested by the Kolmogorov-

189 Smirnov method. The remaining study variables were qualitative and were studied by a descriptive 190 analysis.

191 When the study variable was continuous and normally distributed, Student's t-test was used

192 to determine whether the inter-group differences were significant. For the qualitative variables, the

193 chi-square test was applied to determine the differences between the groups. The statistical power

194 of the study for the temporal variables was $82 \%$. Multiple linear regression models were obtained

195 for the first and second stages and for the total duration of delivery.

196 All statistical analyses were performed using IBM SPSS 19 statistical software (SPSS Inc.,

197 Chicago, USA). The significance level was set at $\mathrm{p}<0.05$.

198

199

3. Results

200

Figure 1 shows the flow diagram of the sample selection procedure used.

201

Figure 1. Sample selection procedure

202

As shown in Figure 1, five women in EG and six in EG had to leave the study due to 203

pathologies such as the risk of premature birth, or delayed intrauterine growth, pregnancy-induced hypertension, or premature rupture of the membranes.

205

Table 1 shows that EG and CG presented similar populational characteristics, with no 206 significant differences in age, weight, or height at baseline, or in parity (Student's t-test; $\mathrm{p}>0.05$ ).

207 Neither were there any statistically significant differences in the administration of oxytocin in 208 order to induce labor (Student's t-test; $\mathrm{p}=0.390$ ). The use of anesthesia was similar in both groups 209 (Student's t-test; $\mathrm{p}=0.092$ ). 
Table 1: Baseline characteristics of the study population.

211

There were no significant differences between $\mathrm{EG}$ and $\mathrm{CG}$ in the reason for hospital

212 admission (Pearson's chi-square: $\mathrm{p}=0.776$ ), and in both groups a high percentage of women were

213 admitted with the diagnosis of latent phase of labor) (EG 58.5\% vs. CG 64.1\%).

214 The intensity of the physical exercise was monitored on a daily basis; the women were

215 asked to indicate their perceived level of exercise intensity, according to the Borg scale. The aim

216 was to maintain a daily score ranging between 12-14 ("somewhat hard" on the Borg scale) and

217 corresponding to moderate intensity.

218 The onset of labor was more likely to be spontaneous in EG than in CG (70.8\% versus $21960.9 \%$, respectively; $\mathrm{p}>0.05)$, and was less likely to be induced $(21.5 \% \mathrm{vs.} 29.7 \%$, respectively, $220 \mathrm{p}>0.05)$. The main reason for the induction of labor was premature rupture of the membranes at 221 term.

The duration of gestation in EG and CG was examined to determine whether physical 223 exercise during pregnancy produced any alteration in this respect. No significant differences were observed between EG (281 days [277 - 286.50]) and CG (281 days [275.25 - 286.75]) ( $\mathrm{p}=0.996)$

225 (see Figure 2). However, neonatal birth weight was significantly lower in EG than in CG $226(\mathrm{p}=0.011)$

Figure 2: Days of gestation of labor, expressed in minutes. Significant differences were observed in this respect $(p<0.001)$ (see 230 Table 2 and Fig. 3). 
234 and CG (6 hours $45 \mathrm{~min})(\mathrm{p}<0.001)$. The difference of just over one hour for the second stage was 235 statistically significant $(\mathrm{p}=0.007)$. However, for the third stage there were no statistically 236 significant differences, and both groups presented similar times. The total delivery time for EG 237 was almost three hours less than that for CG.

Table 3 shows the results of the multivariate regression models for the first and second stages of labor, and for the total time of delivery.

The variables that influenced delivery times were induced labor, the use of epidural/subdural analgesia, the administration of oxytocin, and the performance of physical exercise. The duration of dilation was on average 88.87 minutes greater in CG than in EG, adjusting for all other variables, and 35.83 minutes greater until expulsion. The total delivery time was on average 139.13 minutes less in EG, adjusting for all other variables. The $\mathrm{R}^{2}$ value for this model was 0.40 , which indicates that these four variables accounted for $40 \%$ of the total variability of delivery duration.

\section{Discussion}

The first and second stages of labor were shorter for women who performed moderate physical exercise in water, following the SWEP guidelines, than for those who did not. The strengths of this study are the large number of participants, the high rate of follow-up, and the fact that the exercise program used (the SWEP method) was specially designed for pregnant women. Among its limitations are the difficulty of recruiting suitable participants, arising in part from the lack of information available in the health services to resolve doubts concerning physical exercise

254 during pregnancy. Another limitation is that, in the linear regression model, in which some of the 255 study hypotheses were not met, no residual normality was detected for the times of dilation, 256 expulsion, and total delivery. Furthermore, the study population included only women who were 
257 not at risk during pregnancy, and therefore our results cannot be extrapolated to groups that include

258 women with risky pregnancies.

259 Salvesen et al. (2014) ${ }^{19}$ conducted a study with similar characteristics, with a study

260 population of 855 pregnant women who performed aerobic and strength-building exercises from

261 weeks 20 to 36 of their pregnancy. This program consisted of a weekly group session led by a

262 physiotherapist. The women were encouraged to conduct a 45-minute program at home, at least

263 twice weekly, and to record this activity in a personal training diary. The authors concluded that

264 the performance of physical exercise did not influence the duration of the stages of birth, possibly

265 because the exercise was not supervised at all times by a professional, and so the correct execution

266 of the procedure could not be evaluated.

In our study, neonatal birthweight was significantly lower in EG than in $\mathrm{CG}(\mathrm{p}=0.011)$,

which is consistent with the findings of Barakat et al. $(2010)^{20}$ that physical exercise during

pregnancy tends to reduce the birthweight, but has no influence on gestational age at birth.

However, Perales et al. (2016) ${ }^{21}$, in a study with 166 pregnant women (83 in EG and 83 in

$\mathrm{CG}$ ), with an average age of 31.6 (SD 3.80) years, and who presented an uncomplicated singleton

272 pregnancy, reported that participation in a physical exercise program during pregnancy is

associated with a shorter first stage, with no significant differences in the duration of the second

and third stages. This contrasts somewhat with the results of our study, according to which women

who perform moderate physical exercise in water during the second and third trimesters of

pregnancy present a significantly shorter first and second stage duration, with no significant differences in that of the third stage.

Silveira \& Segre $(2012)^{22}$ carried out a prospective study of 66 pregnant women, aged

between 18 and 30 years, with 37 in EG and 29 in CG. The women in EG performed moderate 
280 exercise twice a week for 50 minutes from week 20 of gestation until birth. These authors

281 concluded that taking part in an exercise program during pregnancy influenced the type of birth,

282 increasing the rate of vaginal deliveries. Similar findings were obtained by Poyatos-León et al ${ }^{23}$,

283 who conducted a meta-analysis in 2015 and reported that regular exercise during pregnancy

284 seemed to increase the likelihood of healthy pregnant women achieving a eutocic birth. However,

285 this conclusion was not corroborated by our results, according to which the rates of spontaneous

286 deliveries in CG and EG were similar (56.25\% vs. 63.07\%), as was that of cesarean section

$287(14.06 \%$ vs. $12.30 \%)$.

288 Barakat et al. (2009) $)^{24}$ conducted a study of 160 pregnant women, 80 in each group. Those

289 in EG performed 26 weeks of moderate-intensity exercises, with three sessions per week,

290 beginning at week 12-13 of gestation and ending at week 38-39 of gestation. These authors

291 reported that resistance training at moderate intensity, performed during the second and third

292 trimesters of pregnancy, does not affect the type of birth, a finding corroborated by our own results.

293 However, these authors did not obtain satisfactory results for the duration of the first and second

294 stages of birth. This study, in which statistically significant differences were obtained between EG

295 and CG, had a similar design to our own, the main difference between the two being that in ours

296 the exercises were performed in water, and the training program used, the SWEP method, was

297 designed especially for this study.

298 Our study shows that moderate, supervised resistance exercise does not endanger the health

299 status of healthy pregnant women or that of the fetus, which is in accordance with the conclusions

300 of Petrov Fieril, Glantz \& Fagevik Olsen ${ }^{25}$, in whose study the women in EG performed a

301 supervised resistance exercise program, twice weekly for 12 weeks (from week 14 to week 25 of

302 gestation), with a moderate to vigorous activity level. 


\section{Conclusions}

Moderate physical exercise in water is associated with a reduced total time of labor and

305 birth. In our study, the first and second stages of labor were significantly shorter in EG. Moreover,

306 this activity increases the rate of eutocic birth, which enables the mother to recover more quickly

307 and to make rapid skin-to-skin contact with the baby. In vaginal and instrumental deliveries, early

308 skin-to-skin contact is sometimes delayed, when examination by the neonatologist is required,

309 which is why spontaneous deliveries are more likely to be associated with rapid skin-to-skin

310 contact. This, in turn, facilitates immediate breastfeeding.

311 As possible areas for future research, it would be interesting to investigate the use of this

312 type of therapy in relation to health-related quality of life in healthy pregnant women and to

313 consider how, during the postpartum period, it might influence quality of life, postpartum

314 depression, postpartum fatigue, stress urinary incontinence, and abdominal diastasis. It could also

315 be useful to study the economic impact of applying this type of therapy during pregnancy and the

316 puerperium, in terms of reducing the need for medical consultations during pregnancy, with their

317 associated costs, in comparison with the cost of implementing the program through healthcare

318 services.

319

320

321 


\section{References}

323 1. ACOG. Physical activity and exercise during pregnancy and the postpartum period.

324 Committee Opinion No. 650. Obstet Gynecol. 2015;126:e135-e142.

325 2. Sui Z, Turnbull D, Dodd J. Enablers of and barriers to making healthy change during

326 pregnancy in overweight and obese women. Australas Med J. 2013;6(11):565-577.

327 doi:10.4066/AMJ.2013.1881

328 3. Pelaez M. Efecto del ejercicio físico durante el embarazo sobre la ganancia excesiva de 329 peso y sus consecuencias. 2011. https://serviciosgate.upm.es/tesis/tesis/6766.

330 4. Barakat R, Pelaez M, Lopez C, Lucia A, Ruiz JR. Exercise during pregnancy and 331 gestational diabetes-related adverse effects: a randomised controlled trial. Br J Sports Med.

332 2013;(Journal Article). doi:10.1136/bjsports-2012-091788

333 5. Genest DS, Falcao S, Gutkowska J, Lavoie JL. Impact of exercise training on

334 preeclampsia: potential preventive mechanisms. Hypertension. 2012;60(5):1104-1109.

335 doi:10.1161/HypertensionAHA.112.194050

336 6. da Silva SG, Hallal PC, Domingues MR, Bertoldi AD, Silveira MF. A randomized

337

338

339

340

341

342

343 controlled trial of exercise during pregnancy on maternal and neonatal outcomes: results from the PAMELA study. Int J Behav Nutr Phys Act. 2017;14(1):175. doi:10.1186/s12966-017-06326

7. Barakat R, Pelaez M, Lopez C, Montejo R, Coteron J. Exercise during pregnancy reduces the rate of cesarean and instrumental deliveries: results of a randomized controlled trial. $J$ Matern-Fetal Neonatal Med Off J Eur Assoc Perinat Med Fed Asia Ocean Perinat Soc Int Soc Perinat Obstet. 2012;25(11):2372-2376. doi:10.3109/14767058.2012.696165

344 8. Castillo-Obeso M. Disfruta de tu embarazo en el agua: actividades acuáticas para la 345 mujer gestante. Barcelona: Inde; 2002.

346 9. Ministerio de Sanidad, Seguridad Social e Igualdad. Guía de práctica clínica de atención 347 en el embarazo y puerperio. 2017.

$348 \mathrm{http} / / \mathrm{msssi}$.es/ca/organizacion/sns/planCalidadSNS/pdf/Guia_practica_AEP.pdf. Accessed 349 January 12, 2017.

350 10. Aguilar-Cordero MJ, Rodríguez-Blanque R, Sánchez-García JC, Sánchez-López AM, Baena-García L, López-Contreras G. Influencia del programa SWEP (Study Water Exercise Pregnant) en los resultados perinatales: protocolo de estudio. Nutr Hosp. 2016;33(1):162-176. doi:10.20960/nh.28

354 11. Borg GA. Psychophysical bases of perceived exertion. Med Sci Sports Exerc.

355 1982;14(5):377-381.

356 12. De Groof D, Vangeenderhuysen C, Juncker T, Favi RA. [Impact of the introduction of a partogram on maternal and perinatal mortality. Study performed in a maternity clinic in Niameny, Niger]. Ann Société Belge Médecine Trop. 1995;75(4):321-330.

13. Lennox CE, Kwast BE, Farley TMM. Breech labor on the WHO partograph. Int J Gynecol Obstet. 1998;62(2):117-127. doi:10.1016/S0020-7292(98)00083-6

14. Napoles D, Bajuelo Paez E, Tellez Cordova M del S, Couto Núñez D. El partograma y las desviaciones del trabajo de parto. MEDISAN. 2004;8(4):64-72.

363 15. Tinker A, Koblinsky MA. Hacia una maternidad segura-Documentos para discusión de 364 Banco Mundial ; 202S. Washington, D.C.: Banco Internacional de Reconstrucción y Fomento /

365 Banco Mudial; 1994.

366 http://scholar.googleusercontent.com/scholar?q=cache:BB6GXXyfzIkJ:scholar.google.com/+Tin

367 ker+A,+Koblinsky+MA.+\%22Hacia+una + maternidad + segura $\% 22 \& h l=e s \& a s \_s d t=0,5$. 
368 Accessed October 2, 2016.

369 16. Walraven GL. WHO partograph. The Lancet. 1994;344(8922):617.

370 17. WHO Maternal Health and Safe Motherhood. Preventing prolonged labour : a practical

371 guide: the partograph. 1994. http://www.who.int/iris/handle/10665/58903. Accessed October 2,

3722016.

373 18. Barakat R, Lucia A, Ruiz JR. Resistance exercise training during pregnancy and

374 newborn's birth size: a randomised controlled trial. Int J Obes. 2009;33(9):1048-1057.

375 doi:10.1038/ijo.2009.150

376 19. Salvesen KÅ, Stafne SN, Eggebø TM, Mørkved S. Does regular exercise in pregnancy

377 influence duration of labor? A secondary analysis of a randomized controlled trial. Acta Obstet

378 Gynecol Scand. 2014;93(1):73-79. doi:10.1111/aogs.12260

379 20. Barakat R, Cordero Y, Rodríguez G, Zakynthinaki MS, Stirling J. Actividad física

380 durante el embarazo, su relación con la edad gestacional materna y el peso de nacimiento.

381 RICYDE Rev Int Cienc Deporte. 2010;6(20):205-217. doi:doi:10.5332/ricyde2010.02003

382 21. Perales M, Calabria I, Lopez C, Franco E, Coteron J, Barakat R. Regular exercise

383 throughout pregnancy is associated with a shorter first stage of labor. Am J Health Promot.

384 2016;30(3):149-154. doi:10.4278/ajhp.140221-QUAN-79

385 22. Silveira LC da, Segre CA de M. Physical exercise during pregnancy and its influence in

386 the type of birth. Einstein São Paulo. 2012;10(4):409-414. doi:10.1590/S1679-

38745082012000400003

388 23. Poyatos-León R, García-Hermoso A, Sanabria-Martínez G, Álvarez-Bueno C, Sánchez389 López M, Martínez-Vizcaíno V. Effects of exercise during pregnancy on mode of delivery: a 390 meta-analysis. Acta Obstet Gynecol Scand. 2015;94(10):1039-1047. doi:10.1111/aogs.12675

391 24. Barakat R, Ruiz JR, Stirling JR, Zakynthinaki M, Lucia A. Type of delivery is not 392 affected by light resistance and toning exercise training during pregnancy: a randomized 393 controlled trial. Am J Obstet Gynecol. 2009;201(6):590.e1-6. doi:10.1016/j.ajog.2009.06.004

394 25. Petrov-Fieril K, Glantz A, Fagevik Olsen M. The efficacy of moderate-to-vigorous 395 resistance exercise during pregnancy: a randomized controlled trial. Acta Obstet Gynecol Scand. 396 2015;94(1):35-42. doi:10.1111/aogs.12525 


\section{Figure 1 (on next page)}

Flow diagram 


\section{Manuscript to be reviewed}
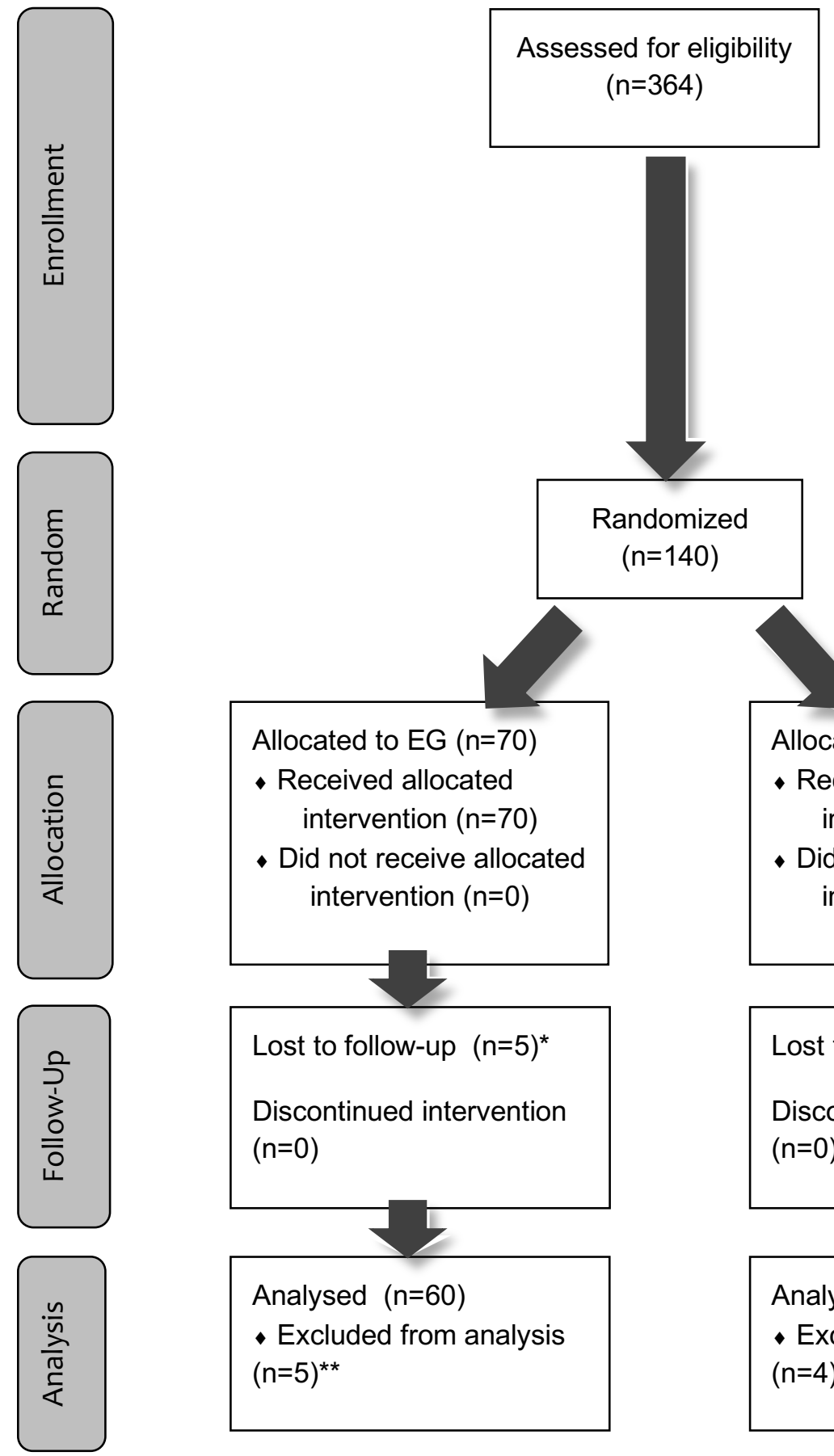

Analysed $(n=60)$

- Excluded from analysis $(n=5)^{* *}$

Allocated to EG $(n=70)$

- Received allocated intervention $(n=70)$

- Did not receive allocated intervention $(n=0)$

Lost to follow-up $(n=5)^{*}$

Discontinued intervention $(n=0)$

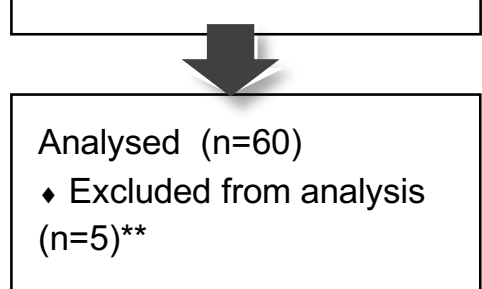

Excluded $(\mathrm{n}=224)$

- Not meeting inclusion criteria $(n=122)$

- Declined to participate $(n=82)$

- Other reasons $(n=20)$

Randomized

$(n=140)$

* Complicaciones durante la gestación:

EG; 1 DIG, 1 TPB, 1P-IH, 2 PRM

CG: 2 P-IH, 1 DIG, 1 TPB, 2 PRM

** Instrumental delivery and cesarean section

DIG: Delayed Intrauterine Growth; TPB: Threat of Premature Birth; P-IH: PregnancyInduced Hypertension; PRM: Premature Rupture of Membranes. 
Figure 2

Days of gestation

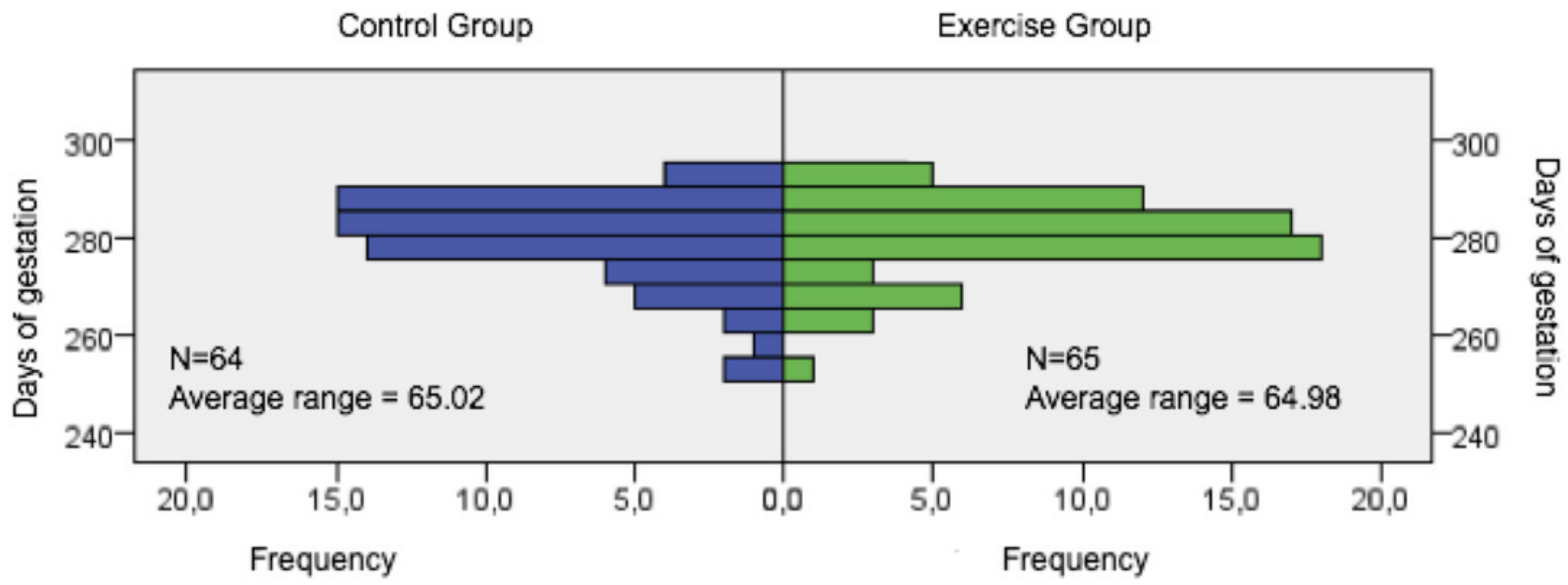


Figure 3

Total duration (minutes) of labour-delivery in the study groups

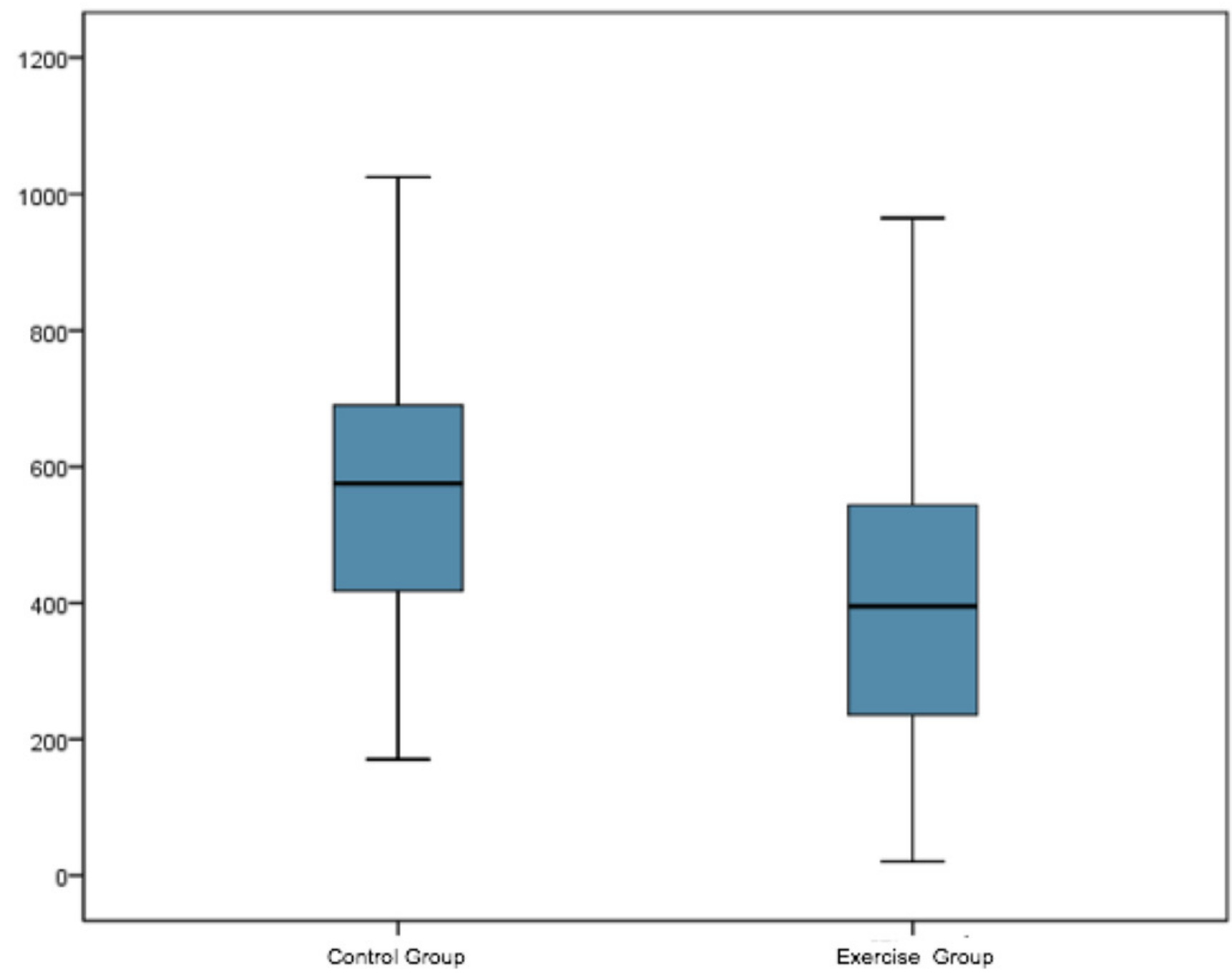


Table $\mathbf{1}$ (on next page)

Baseline characteristics of the sample 
Table 1: Baseline characteristics of the sample

\begin{tabular}{|c|c|c|c|}
\hline Characteristic & $\begin{array}{l}\text { Exercise Group } \\
\qquad n=65\end{array}$ & $\begin{array}{c}\text { Control Group } \\
\qquad n=64\end{array}$ & p-value \\
\hline \multirow[t]{2}{*}{ Maternal age, years. (Mean \pm SD) } & $32.12 \pm 4.43$ & $30.58 \pm 4.75$ & \multirow{2}{*}{0.331} \\
\hline & $21-43$ & $22-43$ & \\
\hline Height (Mean \pm SD) & $1.646 \pm 0.06$ & $1.651 \pm 0.05$ & 0.604 \\
\hline Weight first trimester (Mean \pm SD) & $67.07 \pm 12.23$ & $67.89 \pm 12.58$ & 0.71 \\
\hline Weight third trimester (Mean $\pm S D$ ) & $75.35 \pm 12.13$ & $79.05 \pm 11.64$ & 0.079 \\
\hline BMI first trimester (Median [Q1-Q3]) & $23.89[21.52-27.51]$ & $24.01[21.78-26.58]$ & 0.953 \\
\hline BMI third trimester (Mean \pm SD) & $27.76 \pm 4.03$ & $29.03 \pm 4.45$ & 0.092 \\
\hline Multiparous $\mathrm{n}(\%)$ & $20(30.77 \%)$ & $17(26.56 \%)$ & 0.739 \\
\hline Oxytocin n(\%) & $19(29.7 \%)$ & $14(21.5 \%)$ & 0.39 \\
\hline Anesthesia (Epidural/Subdural) n(\%) & $55(85.9 \%)$ & $47(72.3 \%)$ & 0.092 \\
\hline Duration of gestation (Mean \pm SD) & $280.09 \pm 8.26$ & $279.70 \pm 8.92$ & 0.996 \\
\hline Neonatal birthweight (Mean \pm SD) & $3,259.00 \pm 564.40$ & $3,477.11 \pm 414.51$ & 0.011 \\
\hline Skin-Skin contact $n(\%)$ & $53(81.5 \%)$ & $51(79.7 \%)$ & 0.790 \\
\hline
\end{tabular}


Table 2 (on next page)

Duration of labor (minutes) 
Table 2: Duration of labor (minutes).

\begin{tabular}{|c|c|c|c|}
\hline & $\begin{array}{c}\text { CG } \\
n=60 \\
\text { Median[Q1-Q3 }{ }^{\mathrm{a}}\end{array}$ & $\begin{array}{c}\text { EG } \\
n=60 \\
\text { Median[Q1-Q3] }\end{array}$ & p-value \\
\hline $1^{\text {st }}$ stage & $405.00[295.00-498.75]$ & $260.00[137.50-390.00]$ & $<0.001$ \\
\hline $2^{\text {nd }}$ stage & $152.50[70.00-210.00]$ & $90.00[30.00-187.50]$ & 0.007 \\
\hline \multirow[t]{2}{*}{$3^{\text {rd }}$ stage } & $8.00[5.00-10.00]$ & $5.00[5.00-10.00]$ & 0.383 \\
\hline & Mean $\pm \mathbf{S D}^{\mathbf{b}}$ & Mean $\pm \mathbf{S D}^{\mathfrak{b}}$ & \\
\hline Duration of labor & $561.30 \pm 199.94$ & $389.33 \pm 216.18$ & $<0.001$ \\
\hline
\end{tabular}

2

3 a: Median[Q1-Q3]: Median [Quartile 1 - Quartile 3]

4 b: Mean \pm SD: Mean \pm Standard Deviation

5

6 


\section{Table 3 (on next page)}

Regression models; first stage, second stage and total time of delivery 
1 Table 3: Regression models; first stage, second stage and total time of delivery.

\begin{tabular}{lcccc}
\hline \hline \multicolumn{6}{l}{ Regression model for time of the first stage (min) } \\
\hline \hline & $\beta$ & standard error & $\mathrm{P}$ & $95 \% \mathrm{Cl}$ \\
\hline (Constant) & 9.767 & 68.016 & .886 & $(-125.05,144.59)$ \\
Induced Start & 105.111 & 32.217 & .001 & $(41.25,168.97)$ \\
Epidural analgesia & 149.135 & 36.752 & .000 & $(76.29,221.98)$ \\
Exercise Group & 88.870 & 29.088 & .003 & $(31.21,146.52)$ \\
\hline \hline
\end{tabular}

Regression model for time of the second stage (min)

\begin{tabular}{lcccc}
\hline \hline (Constant) & .609 & 28.179 & .983 & $(-55.22,56.43)$ \\
Epidural analgesia & 64.787 & 15.629 & .000 & $(33.82,95.75)$ \\
Exercise Group & 35.833 & 13.211 & .008 & $(9.66,62.01)$ \\
\hline \hline
\end{tabular}

\section{Regression model for total time of delivery (min)}

\begin{tabular}{lcccc}
\hline \hline (Constant) & -27.412 & 70.228 & .697 & $(-166.55,111.72)$ \\
Induced Start & 119.548 & 37.605 & .002 & $(45.05,194.05)$ \\
Epidural analgesia & 221.990 & 39.406 & .000 & $(143.92,300.06)$ \\
Exercise Group & 139.133 & 32.685 & .000 & $(74.38,203.89)$ \\
Oxitocyn & 96.937 & 54.799 & .080 & $(-11.63,205.50)$ \\
\hline \hline
\end{tabular}

